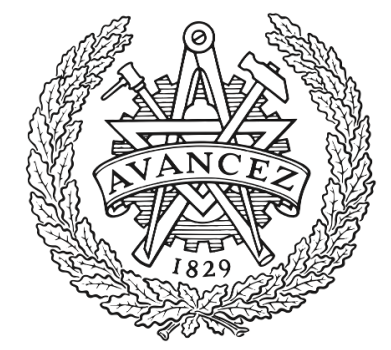

CHALMERS

UNIVERSITY OF TECHNOLOGY

\title{
SOx storage and release kinetics for ceria-supported Pt
}

Downloaded from: https://research.chalmers.se, 2023-04-26 15:02 UTC

Citation for the original published paper (version of record):

Happel, M., Kylhammar, L., Carlsson, P. et al (2009). SOx storage and release kinetics for ceria-supported Pt. Applied Catalysis B: Environmental, 91(3-4): 679-682.

http://dx.doi.org/10.1016/j.apcatb.2009.07.002

N.B. When citing this work, cite the original published paper. 


\title{
$\mathrm{SO}_{x}$ storage- and release kinetics for ceria
}

\section{supported platinum}

\author{
Markus Happel ${ }^{\mathrm{a}}$, Lisa Kylhammar ${ }^{\mathrm{b}, \mathrm{d}}$, \\ Per-Anders Carlsson ${ }^{\mathrm{b}, \mathrm{d}, *}$, Jörg Libuda ${ }^{\mathrm{a}}$, Henrik Grönbeck ${ }^{\mathrm{c}, \mathrm{d}}$ \\ and Magnus Skoglundh b,d \\ ${ }^{a}$ Department of Chemistry and Pharmacy, Friedrich-Alexander-University \\ Erlangen-Nuremberg, D-91058 Erlangen, Germany \\ ${ }^{\mathrm{b}}$ Department of Chemical and Biological Engineering, Chalmers University of \\ Technology, SE-412 96 Göteborg, Sweden \\ ${ }^{\mathrm{c}}$ Department of Applied Physics, Chalmers University of Technology, SE-412 96 \\ Göteborg, Sweden \\ ${ }^{\mathrm{d}}$ Competence Centre for Catalysis, Chalmers University of Technology, SE-412 96 \\ Göteborg, Sweden
}

\begin{abstract}
The $\mathrm{SO}_{x}$ storage- and release kinetics on $\mathrm{CeO}_{2}$ have been studied by lean $\mathrm{SO}_{x}$ adsorption and temperature programmed desorption for different pairwise configurations of individual monolith samples, i.e., $\mathrm{Pt} / \mathrm{CeO}_{2}+\mathrm{SiO}_{2}, \mathrm{Pt} / \mathrm{SiO}_{2}+\mathrm{CeO}_{2}$, $\mathrm{CeO}_{2}+\mathrm{Pt} / \mathrm{SiO}_{2}$ and $\mathrm{CeO}_{2}+\mathrm{SiO}_{2}$. In the case of sole ceria, lean $\mathrm{SO}_{x}$ adsorption proceeds both via $\mathrm{SO}_{2}$ and $\mathrm{SO}_{3}$ adsorption although the latter channel is kinetically favored. Hence, the rate of $\mathrm{SO}_{2}$ oxidation is crucial for the overall $\mathrm{SO}_{x}$ storage kinetics. It is found that physical contact between Pt and ceria is important for the storage process. This is attributed to efficient transport routes for $\mathrm{SO}_{x}$ (surface
\end{abstract}


diffusion and spill-over processes) and/or specific adsorption sites at the platinumceria interface. The main route for $\mathrm{SO}_{x}$ release is found to be thermal decomposition where the effect of platinum is minor, although, in similarity with the storage kinetics, an indirect role could be present. Different mechanistic scenarios for $\mathrm{SO}_{x}$ adsorption are addressed and discussed which may serve as a guide for future experiments.

Key words: sulfur trap, adsorption, desorption, $\mathrm{SO}_{2}$ oxidation, noble metal-support interaction, $\mathrm{CeO}_{2}, \mathrm{Pt}$

\section{Introduction}

Energy-efficient solutions for propulsion within the transportation sector are likely to involve oxygen excess (lean) combustion [1]. A possible concept to reduce the $\mathrm{NO}_{x}$ levels in the resulting (net-) lean exhausts is $\mathrm{NO}_{x}$ storage catalysis [2]. However, the $\mathrm{NO}_{x}$ storage catalyst (NSC) has a high affinity towards sulfur oxides $\left(\mathrm{SO}_{x}\right)$ which poison the storage sites and lead to severe deactivation. Thus, the NSC should not be exposed to even small amounts of $\mathrm{SO}_{x}$ originating from fuels and/or lubricants. It is challenging to find appropriate solutions to this durability issue as emission standards need to be fulfilled over an expected useful period [4]. One strategy is to prevent $\mathrm{SO}_{x}$ from reaching the NSC by including a, so-called, sulfur trap upstream the NSC in the aftertreatment system. Two different types of upstream sulfur traps have been proposed earlier, i.e., disposable [3] and regenerable [5]. Here, the latter is considered to be used under continuously lean conditions.

\footnotetext{
* Corresponding author.

Email address: perc@chalmers.se (Per-Anders Carlsson).
} 
Other concepts based on, for example, incorporation of $\mathrm{SO}_{x}$ trapping materials in the NSC formulation that can store and release $\mathrm{SO}_{x}$ under lean and rich conditions, respectively, have also been reported [6,7]. Such systems, however, are not treated here.

In a previous study [5] it has been found that for continuously lean conditions, $\mathrm{CeO}_{2}$-based materials are suitable for regenerable $\mathrm{SO}_{x}$ traps. The design target in this case was to store $\mathrm{SO}_{x}$ by adsorption below $500^{\circ} \mathrm{C}$ and release stored $\mathrm{SO}_{x}$ by thermal desorption above $600^{\circ} \mathrm{C}$. The addition of platinum was measured to significantly enhance the $\mathrm{SO}_{x}$ storage. However, the actual role of platinum was not clarified although various scenarios were speculated on viz. importance of $\mathrm{SO}_{2}$ oxidation and spill-over of $\mathrm{SO}_{x}$ species. In the present work, the influence of $\mathrm{SO}_{2}$ oxidation and noble metal-support interaction on $\mathrm{SO}_{x}$ adsorption- and desorption kinetics for $\mathrm{Pt} / \mathrm{CeO}_{2}$ is studied in more detail.

\section{Experimental section}

\subsection{Sample preparation and characterization}

The supported platinum samples were prepared by impregnating ceria and silica, respectively, with halogen-free platinum precursors. Ceria (99.5 H.S.A. 514, Rhône-Poulenc) was dispersed in distilled water and an aqueous solution of platinum(II)nitrate $\left(\mathrm{Pt}\left(\mathrm{NO}_{3}\right)_{2}\right.$, Heraeus $\left.\mathrm{GmbH}\right)$ was gently added to the ceria slurry under continuous stirring. The slurry was, thereafter, instantly frozen with liquid nitrogen and freeze-dried. The resulting powder was calcined in air at $600^{\circ} \mathrm{C}$ for $1 \mathrm{~h}$ (heating rate of $4.8^{\circ} \mathrm{C} / \mathrm{min}$ from 25 to $600^{\circ} \mathrm{C}$ ). The corre- 
sponding procedure was used to prepare the $\mathrm{Pt} / \mathrm{SiO}_{2}$ sample by impregnating colloidal silica (20 nm spherical particles, Nyacol 2034DI, Eka Chemicals) with an aqueous solution of tetraammineplatinum(II)nitrate $\left(\mathrm{Pt}\left(\mathrm{NH}_{3}\right)_{4}\left(\mathrm{NO}_{2}\right)_{2}\right.$, Degussa AG). The platinum load was for both catalysts $5 \%$ by weight.

Four types of monolith samples were prepared by immersing bare cordierite monoliths $(\varnothing=20 \mathrm{~mm}$, length $=18 \mathrm{~mm}, 400 \mathrm{cpsi})$ in water slurries containing a binder and, respectively, $\mathrm{Pt} / \mathrm{CeO}_{2}, \mathrm{Pt} / \mathrm{SiO}_{2}, \mathrm{CeO}_{2}$ and $\mathrm{SiO}_{2}$ material. A colloidal ceria sol (10-20 nm spherical particles, Nyacol $\mathrm{CeO}_{2}(\mathrm{Ac})$, Nyacol Nano Technologies) and colloidal silica sol (20 nm spherical particles, Nyacol 2034DI, Eka Chemicals) was used as a binder for the ceria and silica materials, respectively. The coated monolith samples were then dried in air at $90^{\circ} \mathrm{C}$ for 2 min and calcined at $600^{\circ} \mathrm{C}$ for 5 min also in air. By repeating this procedure, $1 \mathrm{~g}$ of the respective coating was attached to each sample. All samples were calcined in air at $600^{\circ} \mathrm{C}$ for $90 \mathrm{~min}$ and stabilized in a mixture of $1 \% \mathrm{CO}$, $0.15 \% \mathrm{C}_{3} \mathrm{H}_{8}$ and $2 \% \mathrm{O}_{2}$ (Ar as balance) using a total flow of $3000 \mathrm{ml} / \mathrm{min}$.

\section{2 $S O_{x}$ adsorption- and desorption experiments}

The adsorption- and desorption experiments were carried out using a gasflow reactor described elsewhere [5]. Briefly, it consists of a horizontal quartz tube surrounded by a metal coil for resistive heating of the gas flow and the samples. Gases are introduced via individual mass flow controllers and the gas temperature in front of the sample is controlled by a Eurotherm regulator. The reactor is equipped with a Fourier transform infrared spectrometer instrument

(MultiGas 2030, MKS instruments) for simultaneous detection of gas phase $\mathrm{SO}_{2}$ and $\mathrm{SO}_{3}$ in the outlet stream. 
Four different sample configurations as depicted in Figure 1 were evaluated by lean $\mathrm{SO}_{x}$ adsorption (100 vol.-ppm $\mathrm{SO}_{2}$ and $7 \% \mathrm{O}_{2}$ in $\mathrm{Ar}$ ) at $250^{\circ} \mathrm{C}$ for 1h followed by a lean temperature programmed desorption $\left(7 \% \mathrm{O}_{2}\right.$ in $\left.\mathrm{Ar}\right)$ by ramping the temperature from 250 to $700^{\circ} \mathrm{C}$ with a ramp rate of $10^{\circ} \mathrm{C} / \mathrm{min}$. The total flow was in both cases $3500 \mathrm{ml} / \mathrm{min}$. This adsorption-desorption sequence was repeated three times.

\section{Results and discussion}

In a previous investigation with the same conditions as the ones used here [5], it was observed that ceria based regenerable $\mathrm{SO}_{x}$ traps initially exhibit a certain (minor) degree of irreversible adsorption. This has been observed also by other authors [refs]. In order to concentrate on the regenerable and reproducible results, the same lean $\mathrm{SO}_{x}$ adsorption-desorption sequence was carried out three times. As the basis for the discussion we use here only the second and third sequence.

In Figure 2 the results for lean $\mathrm{SO}_{x}$ adsorption (third sequence) on the different sample configurations A-D are shown. It is clear that the adsorbed amount of $\mathrm{SO}_{x}$ is much higher for the $\mathrm{Pt} / \mathrm{CeO}_{2}$ sample (A) as compared to bare $\mathrm{CeO}_{2}$ (D). Note that the A geometry is not even saturated during the time frame of the experiment. Based on the second and third adsorption sequence, the average amount of adsorbed $\mathrm{SO}_{x}$ is 406 and $106 \mu \mathrm{mol}$ for the $\mathrm{Pt} / \mathrm{CeO}_{2}$ and $\mathrm{CeO}_{2}$, respectively. This is in accordance with previous observations [5] which intuitively were connected to different routes whereby $\mathbf{S O}_{x}$ adsorbs on, respectively, $\mathrm{Pt} / \mathrm{CeO}_{2}$ and bare $\mathrm{CeO}_{2}$. However, based on previous results it is not clear whether or not the increased $\mathrm{SO}_{x}$ adsorption is 
thanks to the formation of gaseous $\mathbf{S O}_{3}$ over $\mathbf{P t}$ and subsequent adsorption of $\mathrm{SO}_{3}$ on ceria or if $\mathrm{SO}_{3}$ (or some other sulfur species) is transported from the platinum crystallites to ceria via surface diffusion and spill-over processes. Similarly diffusion and spill-over of oxygen to ceria may be important steps. To study the influence of sulphur carrier, here $\mathrm{SO}_{2}$ and $\mathbf{S O}_{3}$, on the $\mathbf{S O}_{x}$ storage, we use as a starting point for the analysis the comparison of present results for $\mathrm{SO}_{x}$ adsorption for the systems with physically separated platinum i.e., configurations B and C. These results are in turn compared with the Pt free system (configuration D).

It is found that the amount of adsorbed $\mathrm{SO}_{x}$ on ceria is higher in the case of the $\mathrm{Pt} / \mathrm{SiO}_{2}$ positioned upstream of the ceria (configuration $\mathrm{B}$ ) as compared to either the downstream position (configuration C) or, even more clearly, the configuration D without Pt. For configuration $\mathrm{B}, \mathrm{SO}_{x}$ is adsorbed during the entire $60 \mathrm{~min}$ period of $\mathrm{SO}_{2}$ exposure, although the $\mathrm{SO}_{x}$ adsorption is minor at the end of the period, as reflected by increasing concentration of outlet $\mathrm{SO}_{2}$. The average amount of adsorbed $\mathrm{SO}_{x}$ is $286 \mu$ mol. Contrary, for configuration $\mathrm{C}$, the outlet $\mathrm{SO}_{2}$ concentration reaches a steady level at about $\mathrm{t}=40$ min. The total $\mathrm{SO}_{x}$ concentration ( the inlet $\mathrm{SO}_{2}$ concentration of 100 vol.-ppm which indicates negligible $\mathrm{SO}_{x}$ adsorption at the end of the measurement. Here the average adsorbed amount of $\mathrm{SO}_{x}$ is $174 \mu \mathrm{mol}$. Similarly, for bare ceria (D) the outlet $\mathrm{SO}_{2}$ concentration reaches a steady level even earlier at about $t=30 \mathrm{~min}$.

The main difference in $\mathrm{SO}_{x}$ adsorption between configuration $\mathrm{B}$ and $\mathrm{C}$ is likely owing to the different $\mathrm{SO}_{2}$ oxidation kinetics for $\mathrm{Pt}$ and $\mathrm{CeO}_{2}$. Provided that the gas phase concentration of $\mathrm{SO}_{3}$ is sufficiently stable (this assumption is supported by thermodynamic calculations not shown here), the present results 
support the earlier suggestion in Refs. $[5,13,14]$ that oxidation of $\mathrm{SO}_{2}$ into $\mathrm{SO}_{3}$ over $\mathbf{P t}$ is important for the overall $\mathrm{SO}_{x}$ adsorption. At the temperature used here, the $\mathrm{SO}_{2}$ oxidation and subsequent sulphate formation on ceria are negligible [5]. Based on results for configuration $\mathrm{B}$ and $\mathrm{C}$, a few scenarios can be envisioned as depicted in Figure 3. For example, given that $\mathrm{SO}_{2}$ and $\mathrm{SO}_{3}$ compete for the same adsorption sites on ceria (scenario I versus scenario II), the present results indicate that $\mathrm{SO}_{3}$ adsorption is kinetically favored. Another explanation could be that the additional $\mathrm{SO}_{x}$ adsorption observed for configuration $\mathrm{B}$ occurs solely via the formation of $\mathrm{SO}_{3}$ thanks to specific adsorption sites for $\mathrm{SO}_{3}$ on the ceria.

Consider again the $\mathrm{SO}_{x}$ adsorption onto the $\mathrm{Pt} / \mathrm{CeO}_{2}$ sample. Likely, the observed high adsorption is only partly explained by the formation of gaseous $\mathrm{SO}_{3}$. The comparison with the corresponding results for physically separated $\mathrm{Pt}$ and ceria (configuration $\mathrm{B}$ ) shows the $\mathrm{Pt} / \mathrm{CeO}_{2}$ adsorbs significantly more $\mathrm{SO}_{x}$. Assuming that the rate of $\mathrm{SO}_{2}$ oxidation into gaseous $\mathrm{SO}_{3}$ is not too different in the two cases (this is supported by the fact that the same amount of $\mathrm{Pt}$ was used in both cases) and that $\mathrm{SO}_{3}$ is sufficiently stable in gas phase, the ceria is in both cases exposed to similar gas composition. Thus, the results indicate that physical contact between platinum and ceria is important for the overall $\mathrm{SO}_{x}$ adsorption process. Although the mechanistic details are difficult to deduce from the present results, we may speculate on different scenarios. If $\mathrm{SO}_{3}$ is not stable in the gas phase under the conditions used here, then $\mathrm{SO}_{2}$ oxidation close to the ceria is important (scenario III). However, as mentioned above, $\mathrm{SO}_{3}$ is probably stable and, thus, a scenario where the $\mathrm{SO}_{3}$ formed on Pt may diffuse on the Pt surface and spill-over to ceria (scenario IV) is possible. The $\mathrm{SO}_{3}$ adsorbed on the ceria may then continue to diffuse 
on the ceria surface as well as into the ceria bulk as was indicated by previous IR spectroscopy experiments [5]. In this case, the corresponding activation barriers for spill-over and diffusion are lower than the energy required for desorption. An expected crucial parameter in this respect is the length of the circumferential Pt-ceria interface. Another scenario that also involves the Pt-ceria interface as an important parameter, is the assumption of specific adsorption sites at the interface accessible for $\mathrm{SO}_{x}$ either directly from gas phase (scenario V) and/or via the platinum or ceria surface (scenario VI).

Hitherto it has been shown that the inclusion of Pt preferable in direct contact with ceria enhances the overall $\mathrm{SO}_{x}$ adsorption on ceria. Turning to the corresponding results for lean $\mathrm{SO}_{x}$ desorption (Figure 4), the role of $\mathrm{Pt}$ is not as pronounced. One obstacle is that for the four geometries the total amount of stored $\mathrm{SO}_{x}$ is different. This may influence the $\mathrm{SO}_{x}$ desorption spectra, especially the peak $\mathrm{SO}_{x}$ desorption. However, despite this issue, a few remarks can be made. The $\mathrm{SO}_{x}$ desorption starts at about $500^{\circ} \mathrm{C}$ for all samples indicating that thermal decomposition of $\mathrm{SO}_{x}$ adsorbed on ceria is important for the release process. Furthermore, comparing configuration A and B (and assuming that the effect of different stored amounts of $\mathrm{SO}_{x}$ is negligible) the peak $\mathrm{SO}_{x}$ desorption occurs at a temperature only about $20^{\circ} \mathrm{C}$ lower for $\mathrm{Pt} / \mathrm{CeO}_{2}$. This indicates that physical contact between Pt and ceria has a minor influence on the desorption and that, again, thermal decomposition of $\mathrm{SO}_{x}$ adsorbed on ceria is the main route. The present results differ from our previous study [5] where $\mathrm{SO}_{x}$ desorption occurred at higher temperatures for ceria samples without $\mathrm{Pt}$. The reason for this is probably due to different sample preparation in the two studies. In the previous study, ceria and $\mathrm{Pt} / \mathrm{CeO}_{2}$, respectively, was attached to monoliths 
using Boehmite as a binder. During sample calcination Boehmite forms alumina which is known to store $\mathrm{SO}_{x}$ also at relatively high temperatures [5]. Thus in the case of the ceria sample where a low amount of $\mathrm{SO}_{x}$ was stored, $\mathrm{SO}_{x}$ desorbed from ceria at low temperatures could be temporarily adsorbed on the alumina until higher temperatures was reached. In the case of $\mathrm{Pt} / \mathrm{CeO}_{2}$, this effect is likely negligible due to the much higher amounts of stored $\mathrm{SO}_{x}$. In the present study a ceria sol was used instead of Boehmite in order to prepare ceria samples with as few components as possible. It should be noted, however, that an indirect effect of $\mathrm{Pt}$ on the $\mathrm{SO}_{x}$ release kinetics for platinum-ceria systems could be observed in the present results. The desorption spectra for configuration $\mathrm{A}$ and $\mathrm{B}$ as well as for $\mathrm{C}$ and $\mathrm{D}$ are similar. For $\mathrm{A}$ and $\mathrm{B}, \mathrm{SO}_{x}$ was stored mainly via $\mathrm{SO}_{3}$ adsorption, whereas for $\mathrm{C}$ and $\mathrm{D}$, storage proceeds mainly via $\mathrm{SO}_{2}$ adsorption. Intuitively, adsorption of $\mathrm{SO}_{3}$ may lead to formation of $\mathrm{SO}_{4}$ species whereas $\mathrm{SO}_{2}$ adsorption may lead to formation of $\mathrm{SO}_{3}$ species in the ceria structure [5]. This indicates that the route for $\mathrm{SO}_{x}$ adsorption is important for the corresponding desorption and, thus, inclusion of platinum has an indirect effect on the $\mathrm{SO}_{x}$ release kinetics for platinum-ceria systems.

\section{Concluding remarks}

In summary we have shown that lean $\mathrm{SO}_{x}$ storage on platinum-ceria systems occurs both via adsorption of $\mathrm{SO}_{2}$ and $\mathrm{SO}_{3}$, where the latter is kinetically favored. Thus, the rate of $\mathrm{SO}_{2}$ oxidation is important for the overall $\mathrm{SO}_{x}$ storage kinetics. Moreover, physical contact between platinum and ceria is important 
for the overall $\mathrm{SO}_{x}$ storage kinetics possibly by providing new transport routes (diffusion and spill-over) and/or adsorption sites at the platinum-ceria interface for $\mathrm{SO}_{x}$. Thermal decomposition of $\mathrm{SO}_{x}$ species seems to be the main route for $\mathrm{SO}_{x}$ desorption and thus platinum plays a minor role. However, platinum may play an indirect role as the route for $\mathrm{SO}_{x}$ storage, i.e., via $\mathrm{SO}_{2}$ or $\mathrm{SO}_{3}$ adsorption, seems to influence the $\mathrm{SO}_{x}$ desorption kinetics.

\section{Acknowledgments}

Support from COST Action D41 and the Swedish EMFO program, and the financial support from Knut and Alice Wallenberg Foundation, Dnr KAW 2005.0055, is gratefully acknowledged. Markus Happel and Jörg Libuda thank the Deutsche Forschungsgemeinschaft (DFG) for support and also acknowledge additional support of the DFG within the Excellence Cluster "Engineering of Advanced Materials" in the framework of the excellence initiative. The Competence Centre for Catalysis is hosted by Chalmers University of Technology and financially supported by the Swedish Energy Agency and the member companies AB Volvo, Volvo Car Corporation, Scania CV AB, GM Powertrain Sweden AB, Haldor Topsøe A/S, and The Swedish Space Corporation.

\section{References}

[1] S. Matsumoto, Cattech 4 (2001) 102-109.

[2] N. Takahashi, H. Shinjoh, T. Iijima, T. Suzuki, K. Yamazaki, K. Yokota, H. Suzuki, N. Miyoshi, S. Matsumoto, T. Tanizawa, T. Tanaka, S.-s. Tateishi, K. Kasahara, Catal. Today 27 (1996) 63-69.

[3] H. L. Fang, J. C. Wang, R. C. Yu, C. Z. Wan, K. Howden, SAE technical paper 
series 2003-01-3245.

[4] http://www.dieselnet.com

[5] L. Kylhammar, P.-A. Carlsson, H. Härelind Ingelsten, H. Grönbeck, M. Skoglundh, Appl. Catal. B: Environ. 84 (2008) 268-276.

[6] J. H. Kwak, D. H. Kim, J. Szanyi, C. H. F. Peden, Appl. Catal. B: Environ. 84 (2008) 545-551.

[7] Y. Ji, T. J. Toops, M. Crocker, Catal. Lett. 127 (2009) 55-62.

[8] S. Brunauer, P. H. Emmet, E. Teller, J. Am. Chem. Soc. 60 (1938) 309-319.

[9] T. Wang, A. Vazquez, A. Kato and L. D. Schmidt, J. Catal. 78 (1982) 306-318.

[10] E. Xue, K. Seshan and J. R. H. Ross, J. Catal. 11 (1996) 65-67.

[11] M. Waqif, P. Bazin, O. Saur, J.C. Lavalley, G. Blanchard, O. Touret, Appl. Catal. B: Environ. 11 (1997) 193-205.

[12] M. Y. Smirnov, A. V. Kalinkin, A. V. Pashis, A. M. Sorokin, A. S. Noskov, K. C. Kharas, V. I. Bukhtiyarov, J. Phys. Chem. B. 109 (2005) 11712-11719.

[13] L. Limousy, H. Mahzoul, J. F. Brilhac, P. Gilot, F. Garin, G. Maire, Appl. Catal. B: Environ. 42 (2003) 237-249.

[14] S. Matsumoto, Y. Ikeda, H. Suzuki, M. Ogai, N. Miyoshi, Applied Catalysis B: Environ. 25 (2000) 115-124. 


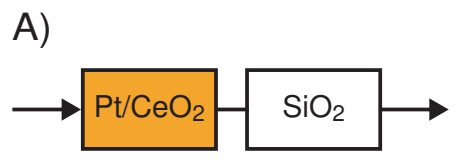

B)

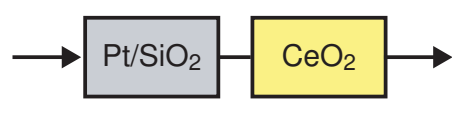

C)

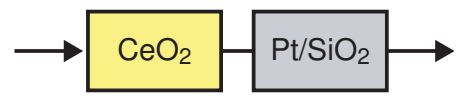

D)

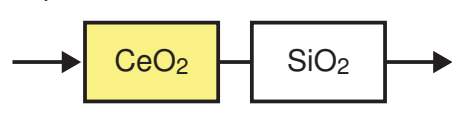

Fig. 1. Schematic picture of the four (A-D) pairwise configurations $5 \% \mathrm{Pt} / \mathrm{CeO}_{2}$, $5 \% \mathrm{Pt} / \mathrm{SiO}_{2}$ and bare $\mathrm{CeO}_{2}$ and $\mathrm{SiO}_{2}$ monolith samples used to study $\mathrm{SO}_{x}$ adsorption- and desorption kinetics. 


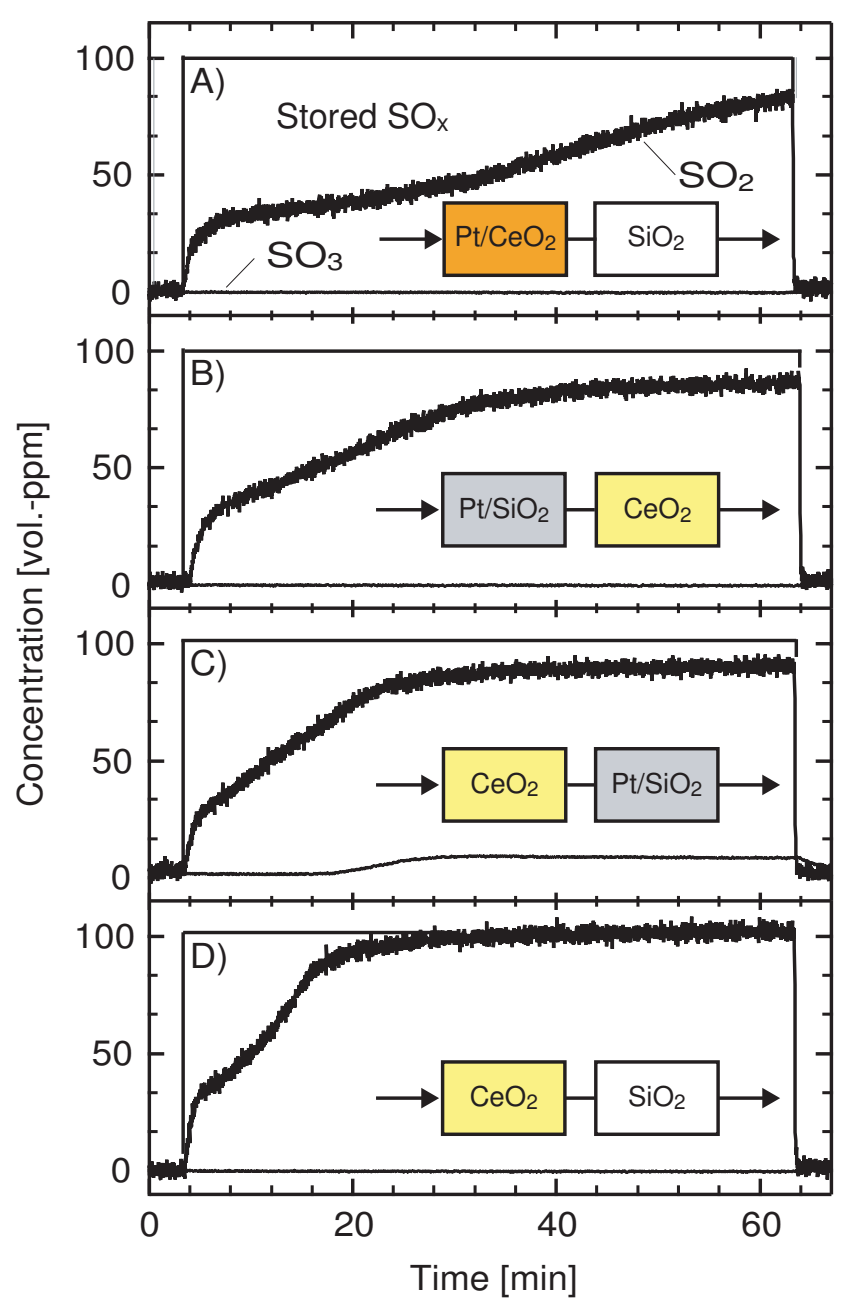

Fig. 2. Outlet $\mathrm{SO}_{2}$ and $\mathrm{SO}_{3}$ concentration traces during lean $\mathrm{SO}_{x}$ adsorption (100 vol.-ppm $\left.\mathrm{SO}_{2} / 7 \% \mathrm{O}_{2} / \mathrm{N}_{2}\right)$ at $250^{\circ} \mathrm{C}$ for different sample configurations. 
I)

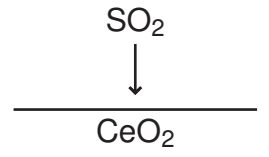

III) $\mathrm{SO}_{2}$

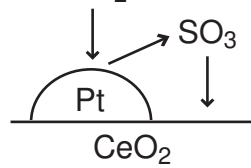

V)

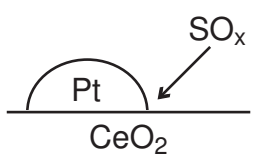

II)

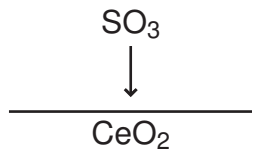

IV) $\mathrm{SO}_{2}$

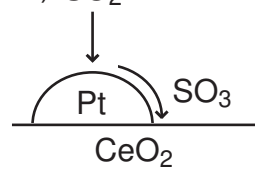

VI) $\mathrm{SO}_{\mathrm{x}}$

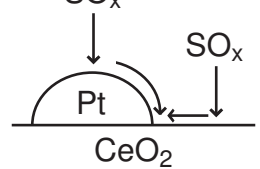

Fig. 3. Schematic picture showing possible routes for adsorption of $\mathrm{SO}_{x}$ on bare ceria and platinum-ceria systems. 


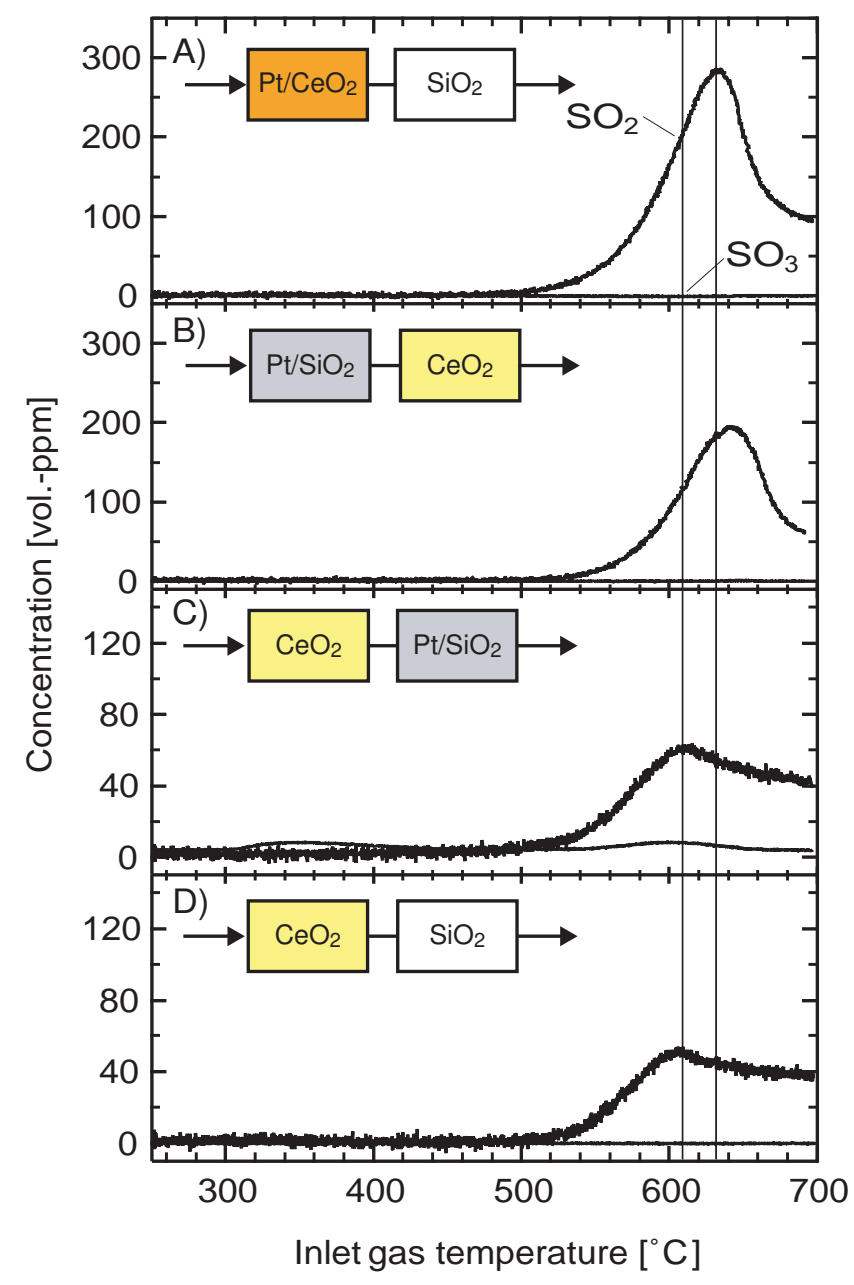

Fig. 4. Outlet $\mathrm{SO}_{2}$ and $\mathrm{SO}_{3}$ concentration traces during lean temperature programmed desorption of $\mathrm{SO}_{x}\left(7 \% \mathrm{O}_{2} / \mathrm{N}_{2}\right)$ for different sample configurations. Ramp rate $10^{\circ} \mathrm{C} / \mathrm{min}$. The two vertical lines show the $\mathrm{SO}_{2}$ peak desorption for configuration $\mathrm{A}$ and $\mathrm{C}$, respectively. 